\title{
On the Value of Earthquake Scenario: The Kathmandu Recent Lesson
}

\author{
Philippe Guéguen $^{1 *}$, Hugo Yepes ${ }^{1,2}$ and Ismael Riedel ${ }^{1}$ \\ ${ }^{1}$ Institute of Earth Science, Université Grenoble Alpes/CNRS/IFSTTAR, Grenoble, France, ${ }^{2}$ Instituto Geofísico, Escuela \\ Politécnica Nacional, Quito, Ecuador
}

Keywords: Nepal earthquake, urban seismology, economic losses, scenarios, seismic risk

\section{OPEN ACCESS}

Edited by:

Gian Paolo Cimellaro,

University of California Berkeley, USA

Reviewed by:

Sean Wilkinson,

Newcastle University, UK

Fabrizio Mollaioli,

Sapienza University of Rome, Italy

*Correspondence:

Philippe Guéguen

philippe.gueguen@ujf-grenoble.fr

Specialty section:

This article was submitted to Earthquake Engineering,

a section of the journal

Frontiers in Built Environment

Received: 31 August 2015 Accepted: 17 December 2015 Published: 08 January 2016

Citation:

Guéguen P, Yepes $H$ and Riedel I (2016) On the Value of Earthquake Scenario: The Kathmandu Recent

Front. Built Environ. 1:26. doi: 10.3389/fbuil.2015.00026
The past two decades have been punctuated by large-scale natural events that produced huge losses whether related to hydrological, atmospheric, or even rare geological hazards. Over the second half of the last century, the total cost of such catastrophes has been multiplied by a factor of 15, clocking up economic losses of around 66 billion dollars per year during the 1990s (Benson and Clay, 2004). Among these phenomena, there are those that cause disasters, i.e., corresponding to infrequent events that have major consequences on the well-being of the region's population, environment, institutions, and financial equilibrium. The predisposition of a region to suffer an infrequent natural disaster is measured by the event's capacity to generate losses that exceed $1 \%$ of GNP, thus resulting in a slow, difficult economic recovery (Munich Re, 2002). According to this definition, geologicalrelated disasters stand out from other natural events: they represent approximately $15 \%$ of the world's natural disasters but account for one-third of all victims and economic losses (World Conference on the Disaster Reduction, 2004). The 2000s were not spared either, with the Indonesian earthquake in 2004, and the earthquakes in Chile and Haiti in 2010. Together, these two quakes generated losses of around 40 billion dollars, and more than 280,000 victims, i.e., 31 and $80 \%$ of economic and human losses caused by natural events respectively, even though earthquakes only represented $6 \%$ of disasters in 2010 (Daniell, 2010). After the 1995 Kobe earthquake that caused economic losses of 178 billion dollars (IFRC, 2002), the 2011 Tohoku earthquake in Japan is known as being the event that caused the greatest direct and indirect costs, on a level to match the scale of the earthquake itself $(\mathrm{Mw}=9)$ : a direct economic impact of around 187 billion dollars was estimated, while indirect sanitary, ecological and economic costs related to the ensuing nuclear disaster are expected to reach a long-standing record level. Such observations should serve as a reminder that although public policies are paying more attention to phenomena related to global climate change, earthquakes still remain the natural events that are most likely to have disastrous consequences. Unlike floods or storms that, although likely to increase in frequency and intensity in the years to come in parallel with the climate change, leave us time to analyze future scenarios, earthquakes are already causing huge disasters now. Looking from a different perspective, Brauman (2010) has analyzed recent years human emergencies from a medical emergency actor's point of view and concluded that earthquakes pose the first order threat to human life that ranks far above acute climatic events occurring near densely populated areas.

The Mw 7.8 Kathmandu earthquake on April 25, 2015 has reminded us of the inequality of populations facing earthquakes (Coburn and Spence, 2002). Economic and human losses obviously not only depend upon the amplitude and severity of the seismic vibrations but also upon the quality of constructions and the financial investment put into direct efforts to design buildings 
and to improve knowledge of seismic hazard (Ohta et al., 1986). In Nepal, the preliminary economic estimate predicts losses representing approximately 18\% of its GNP (CEDIM Forensic Disaster Analysis Group, CATDAT, and Earthquake-Report. com, 2015), which classes this earthquake as a disaster. The region of Kathmandu is exposed to a high seismic hazard (Sapkota et al., 2013; Bilham et al., 2001). The earthquake on April 25, 2015 was a major event that followed on from a long series of events affecting the region along the Himalayan ranges, each time causing numerous fatalities: e.g., the 1905 earthquake $(\mathrm{Mw}=7.8)$ in the Kangra region of India, north-west of Nepal caused 20,000 deaths, 15,000 deaths were accounted for in $1934(\mathrm{Mw}=8.1)$ in the Bihar Nepal region (in the south-eastern part of the country), and the Kashmir earthquake in $2005(\mathrm{Mw}=7.6)$ killed 75,000 people. Low probability/high consequences events are still expected. These events can be at the first order compared with the black swan theory proposed by Taleb (2010), which illustrates a cognitive bias that leads us to the erroneous conclusion that rare phenomena will not happen. People and policy makers may pass over their existence because the return periods are not of the same order of magnitude as the time span of the human life. Moreover, if such events are identified, a monetary cost/benefit analysis of earthquake engineering practices may not be in a positive balance. Incorrectly considering these events as black swans can bring important effects in terms of protection, regulation, and resilience. In fact, only observation over periods longer than the characteristic recurrence time of the phenomena, i.e., on the scale of geological time, can confirm the non-existence of such events (Bilham et al., 2001; Bollinger et al., 2014). However, this is not feasible and, by default, our reasoning is built upon incomplete information, resulting in erroneous predictions. As time passes, we realize that we are getting closer and closer to the appearance of a black swan, particularly since larger earthquakes are possible with even longer return periods.

At the same time, the urban population in the Kathmandu valley has been increasing by around 3.6\% per year (Fort, 2014) over the past decade, reaching 1.5 million people. Since the return period of major earthquakes is so much longer than the periods of recent rapid urbanization, and Jackson (2006) and Holzer and Savage (2013) proclaim that major catastrophes lie ahead. In the Himalaya region, Bilham et al. (2001) projected the urban population growth to one of the possibly overdue Himalayan earthquakes with the same characteristics as the 1905 historical earthquake that yields 200,000 predictable fatalities. Rapid urbanization also amplifies the risk of disasters due to the complex combination of demographic concentration, social exclusion and poverty, accompanied by ignorance of the risks (Fort, 2014). The physical vulnerability of the constructions that ultimately causes fatalities becomes all the greater as the migratory influx presses for new dwellings and infrastructure, resulting in a strong demand for large numbers of buildings to be erected quickly, often at the expense of quality and safety. This pressure thus results in an inappropriate use of space, a low level of compliance with regulations and a good practice that would minimize damage and operation interruptions, and fewer possibilities for transferring or smoothing the risk as consequence of the concentration of goods and decision-making bodies in a single city, which most limits country recovery.

Faced with this situation, and in an attempt to reduce risk, the city of Kathmandu, like many others before (such as Quito, for example), has been analyzed in terms of its seismic risk. At the initiative of GeoHazard International, and with backing from the World Bank and UNESCO, a seismic risk management project was launched (Dixit et al., 1998), with the objectives of educating the public, producing a seismic scenario to simulate losses and operational problems, and implementing an action plan to manage seismic risk. The concept of community for risk assessment and resilience improvement is largely discussed in social sciences (Marsh and Buckle, 2001) and these scenarios participate to this scientific concept. Like Corneiro (2006) who comments that funding is mostly devoted to enhancing numerical modeling of structures rather than to actual and effective solutions of reinforcements, we could question the wisdom of concentrating resources on modeling and representing phenomena rather than implementing building reinforcement actions. However, a study by the USGS claims that a 40-million dollar investment in worldwide prevention measures in the 1990s could have reduced economic losses by 280 million dollars (Benson and Twigg, 2004). Other examples concerning natural disasters also provide favorable ratios [cost of prevention actions to loss-reduction benefits] of around 1:3. Scenarios enable the transfer of scientific knowledge in an understandable manner to local decision-makers and let populations to become aware of the risks and to realize that it is preferable to anticipate natural disaster rather than just to respond to a dramatic event. They also support the view of emergency specialists, who are increasingly insistent on the need to invest in preparation, prevention, and disaster attenuation, particularly in view of the disproportional amounts that international organizations are prepared to spend on emergency rescue and recovery operations conducted hurriedly. Moreover, seismic risk analyses are useful to study the best investment framework for the seismic retrofit of buildings. Several cost-benefit explorations for earthquake damage mitigation showed the attractiveness of retrofitting actions on buildings for long return periods events (Smyth et al., 2004). In general, such studies suggest that retrofitting is desirable (cost-effective) in high seismic hazard regions for all but the very shortest time horizons. These reinforcement investments are on average relatively small compared to the repair and replacement cost of the physical damage subsequently avoided. The economic losses and fatalities following Nepal's earthquake could have been largely reduced if retrofitting actions would have been taken in advance, which is certainly the most difficult action to take. The savings in term of economic losses and human casualties might have been enormous by investing a small portion of the global emergency aid to recovery after the disaster.

Based on the 1934 earthquake, the Kathmandu scenario (Dixit et al., 1998) predicted 40,000 victims, 95,000 people injured, 600,000 left homeless, and the destruction of approximately $60 \%$ of buildings. In spite of the intensity of the last April earthquake, observations suggest that the actual figures are substantially lower. We know that the uncertainty of the 
ground motion prediction model controls the uncertainties of the risk model. The only ground motion record in Kathmandu from the Mw 7.8 earthquake yielded around 0.2 g, i.e., a relatively low value in comparison with the predictions used for the earthquake scenario. It is also characterized by maximum amplitude at a vibration period (about $2 \mathrm{~s}$ ) far from most of the assumed resonance periods of the city's buildings. Very often, seismic ground motions recorded during major earthquakes by seismic networks surprise seismologists and ask about the physical reasons behind them. On the other hand, same reasons are always claimed to explain observations as for Kathmandu (Goda et al., 2015): the most vulnerable buildings suffer more damage, the poorest suburbs without engineering design are the most damaged areas, and design defects are at the origin of most of damaged buildings. However, when the Mw 7.8 earthquake was announced, based on knowledge of the Dixit et al. (1998) scenario, the scientific community expected a disaster at a similar scale as that of the Haiti earthquake of 2010. The Mw 7.3 earthquake located $25 \mathrm{~km}$ from Port-au-Prince caused an economic and human disaster, resulting in more than 230,000 deaths, $60 \%$ of buildings destroyed, and total losses estimated at $120 \%$ of the GNP according to the IMF. Five years later, the country remains dependent upon international aid and the political situation is still equally fragile, due to the postponement of the presidential elections, which are to be funded by foreign countries, threatening the autonomy, independence and democratic sovereignty of the country. The future remains uncertain for Haitians: most schools and universities were destroyed compromising the renewal of the country's active population in the time to come. There are many similarities between these two disasters: in 2010, the human development index in Haiti and Nepal were similar $[0.45$ for the former and 0.458 for the latter, source United Nations Development Programme (2010)], both had experienced considerable population growth over recent decades and seismic rates are equivalent in both countries. Once again the earthquake was not considered, as in the black swan theory, in the sense that several past earthquakes had already occurred while less densely populated at the time. Unlike Kathmandu, however, no exhaustive scenario had been produced in Haiti, and it is much too easy to postulate that this could be one reason for the smaller scale of the Nepalese disaster. Moreover, it is still too soon to fully understand what happened but this earthquake failed to entirely rupture the locked fault close to Kathmandu and a large earthquake appears to be inevitable in future (Bilham, 2015; Avouac et al., 2015).

A different factor that may influence the resilience of a community faced with a natural disaster is the degree of corruption. Ambraseys and Bilham (2011) calculated that $83 \%$ of all deaths from building collapse during earthquakes over the past 30 years occurred in countries that are anomalously corrupt. The Corruption Perceptions Index (Transparency International, 2014) ranks countries and territories based on how corrupt their public sector is perceived to be. It is difficult to make an accurate link of the impact of corruption in Nepal in terms of building collapse but it is surprising to note that for these two countries with equivalent development index, according to the corruption perception index CPI of Transparency International (2014) Haiti in 2010 was ranked 146th in the World while Nepal in 2014 was ranked 126th. Corruption prevents that the money spent in the construction process goes to earthquake-resistant practices and at the end one wonders if the solution is rather to invest in education and training of populations as the most efficient solution for reducing earthquake disasters as described by Twigg (2009).

Over the last century, urbanization growth has dramatically increased the risk in seismic prone areas and many cities in the world have not sufficiently improved their resilience. In this context, we may indeed wonder about the need of producing catastrophe scenarios. In recent years, probability-based prediction solutions have become more popular than deterministic solutions; they integrate all the uncertainties related to the phenomenon in terms of occurrence, including intensity and location, as well as the expected ground motion. However, practical implementation in a country like Nepal is problematic and so representing a specific event (i.e., deterministic approach) remains an essential vector of information and education. The shortcomings of seismic scenarios in that they may never successfully predict the observed consequences of earthquakes (due to the inherent uncertainties of the hazard) may cause maladaptive behavior. For example, the Dixit et al. (1998) scenario predicted more victims: as fewer were observed, as fewer were observed, it is a concern that the population may reject the scientific evidence and decision makers may lose confidence in such tools, while seismological analysis suggests that significant seismic risk remains (Bilham, 2015); however, these scenarios remain essential tools for risk management, preparedness and for increasing the resilience of communities. Based on these scenarios, local initiatives at the community level (Twigg, 2009) are launched, and their representation provides essential support for the long-term reduction of seismic risk in public policy on time spans that are much longer than political mandates. The full implementation of mitigation strategies must however face the challenges of insufficient resources, which is generally cited as being the major obstacle to any prevention policy. The role of scenario in determining impact level is a critical issue (Alexander, 2000). In addition to our current investment in emergency measures, we need to increase investment in resilience, which in time will allow a reduction in relief expenditures and better means of ensuring the economic, political, democratic, and social stability of a country. We need to ensure that investments in disaster reduction measures are on a scale that matches the risks and in developing countries seismic risk scenarios are still important tools in achieving this.

\section{ACKNOWLEDGMENTS}

This work has been supported by a grant from Labex OSUG@2020 (Investissements d'avenir - ANR10 LABX56). 


\section{REFERENCES}

Alexander, D. (2000). Confronting Catastrophe - New Perspectives on Natural Disasters. New York, NY: Oxford University Press.

Ambraseys, N., and Bilham, R. (2011). Corruption kills. Nature 469, 153-155. doi:10.1038/469153a

Avouac, J. P., Meng, L., Wei, S., Wang, T., and Ampuero, J. P. (2015). Lower edge of locked main Himalayan thrust unzipped by the 2015 Gorkha earthquake. Nat. Geosci. 8, 708-711. doi:10.1038/ngeo2518

Benson, C., and Clay, J. E. (2004). Understanding the Economic and Financial Impacts of Natural Disasters, Disaster Risk Management Series 4. The World Bank Edition, Washington, DC, 134.

Benson, C., and Twigg, J. (2004). Measuring Mitigation: Methodologies for Assessing Natural Hazard Risks and the Net Benefits of Mitigation - A Scoping Study. Synthesis Report IFRC/ProVention Consortium. Geneva, 154.

Bilham, R. (2015). Seismology: raising Kathmandu. Nat. Geosci. 8, 582-584. doi:10.1038/ngeo2498

Bilham, R., Gaur, V. K., and Molnar, P. (2001). Himalayan seismic hazard. Science 293, 1442-1444. doi:10.1126/science. 1062584

Bollinger, L., Sapkota, S. M., Tapponnier, P., Kilinger, Y., Rizza, M., and Van der Woerd, J. (2014). Estimating the return times of great Himalayan earthquakes in Eastern Nepal: evidence from the Patu and Bardibas strands of the main frontal thrust. J. Geophys. Res. Solid Earth 119, 7123-7163. doi:10.1002/2014JB010970

Brauman,R.(2010).NaturalDisasters:DoSomething!(Entretiens).Availableat:http:// msf-crash.org/livres/agir-a-tout-prix/catastrophes-naturelles-do-something

CEDIM Forensic Disaster Analysis Group, CATDAT, and Earthquake-Report. com. (2015). Nepal Earthquake - Report \#1 27.04.2015-Situation Report No. 1. Available at: https://www.cedim.de/download/CEDIM_ImpactSummary_ EarthquakeNepal2015_Report1.pdf

Coburn, A., and Spence, R. (2002). Earthquake Protection, Second Édition. Bognor Regis: John Wiley and Sons.

Corneiro, M. C. (2006). Can buildings be made earthquake-safe? Science 312, 204. doi:10.1126/science. 1126302

Daniell, J. (2010). "Damaging Earthquakes Database 2010-The Year in Review," in CEDIM Earthquake Loss Estimation Series Research Report 2011-01, 41. Available at: http://earthquake-report.com/wp-content/uploads/2011/03/ CATDAT-EQ-Data-1st-Annual-Review-2010-James-Daniell-03-03-2011.pdf

Dixit, A. M., Dwelly-Samant, L., Nakarmi, M., Tucker, B., and Pradhanang, S. B. (1998). The Kathmandu Valley Earthquake Management Action Plan. Lalitpur: National Society for Earthquake Technology-Nepal (NSET). Available at: http://geohaz.org/wp/wp-content/uploads/2010/04/ KathmanduValleyEQRiskMgtActionPlan.pdf

Fort, M. (2014). La difficile gestion des risques naturels en Himalaya: une question d'échelle? Le cas du Népal. BAGF - Géographies, 3, 241-256. Available at: https://www.researchgate.net/publication/268802067_Monique_Fort_BAGF_ 2014-3_pp_241-256

Goda, K., Kiyota, T., Pokhrel, R., Chiaro, G., Katagiri, T., Sharma, K., et al. (2015). The 2015 Gorkha Nepal earthquake: insights from earthquake damage survey. Front. Built. Environ 1:1-15. doi:10.3389/fbuil.2015.00008
Holzer, T. L., and Savage, J. C. (2013). Global earthquake fatalities and population. Earthquake Spectra 29, 155-175. doi:10.1193/1.4000106

IFRC. (2002). World Disasters Report 2001: Focus on Community Resilience. Geneva: International Federation of Red Cross and Red Crescent Societies (IFRC), 244.

Jackson, J. (2006). Fatal attraction: living with earthquakes, the growth of villages into megacities, and earthquake vulnerability in the modern world. Philos. Trans. R. Soc. 364, 1911-1925. doi:10.1098/rsta.2006.1805

Marsh, G., and Buckle, P. (2001). Community: the concept of community in the risk and emergency management context. Aust. J. Emerg. Manage. 16, 5-7.

Munich Re. (2002). Topics Annual Review: Natural Catastrophes 2002. Munich. Available at: http://ipcc-wg2.gov/njlite_download.php?id=6219

Ohta, Y., Ohashi, H., and Kagami, H. (1986). "A semi-empirical equation for estimating occupant casualty in an earthquake," in Proceedings of the 8th European Conference on Earthquake Engineering, Lisbon, 2-3, 81-88.

Sapkota, S., Bollinger, L., Klinger, Y., Tapponnier, P., Gaudemer, Y., and Tiwari, D. (2013). Primary surface ruptures of the great Himalayan earthquake in 1934 and 1255. Nat. Geosci. 6, 71-76. doi:10.1038/NGEO1669

Smyth, A. W., Altay, G., Deodatis, G., Erdik, M., Franco, G., Gulkan, P., et al. (2004). Probabilistic benefit-cost analysis for earthquakevdamage mitigation: evaluating measures for apartment houses in Turkey. Earthquake Spectra 20, 171-203. doi:10.1193/1.1649937

Taleb, N. N. (2010). The Black Swan: the Impact of the Highly Improbable. New York, NY: Random House Ed, A Random House trade paperback Coll.

Transparency International. (2014). The Corruption Perceptions Index 2014. Available at: http://www.transparency.org/cpi2014/results

Twigg, J. (2009). Characteristics of a Disaster-Resilient Community: A Guidance Note (version 2). Available at: http://discovery.ucl.ac.uk/1346086/

United Nations Development Programme. (2010). Human Development Report 2010. New York, NY: Palgrave Macmillan. Available at: http://hdr.undp.org/ sites/default/files/reports/270/hdr_2010_en_complete_reprint.pdf

World Conference on the Disaster Reduction. (2004). "Draft Annotated Outline of the Review of the Yokohama Strategy and Plan of Action," in Report A/CONF.206/PC(II)/3 World Conference on the Disaster Reduction (Kobe). Available at: http://www.unisdr.org/2005/wcdr/preparatory-process/prepcom1/pc1-Draft-annotated-outline-review-yokohama-strategy-english.pdf

Conflict of Interest Statement: The authors declare that the research was conducted in the absence of any commercial or financial relationships that could be construed as a potential conflict of interest.

Copyright (C) 2016 Guéguen, Yepes and Riedel. This is an open-access article distributed under the terms of the Creative Commons Attribution License (CC BY). The use, distribution or reproduction in other forums is permitted, provided the original author(s) or licensor are credited and that the original publication in this journal is cited, in accordance with accepted academic practice. No use, distribution or reproduction is permitted which does not comply with these terms. 